\title{
The Two Faces of Open Access
}

\author{
Peter C. Black, Editor-in-Chief ${ }^{\otimes}$ \\ Soc Int Urol J.2021;2(4):193-194 \\ DOI: 10.48083/EROK5654
}

The two faces of open access remain a point of contention in the global world of scientific publishing, and this carries over into the microcosm of urologic publishing. Many of us are part of the research community and all of us are consumers of new research findings. On both sides of the research enterprise-as providers and consumers-our interests are best met by broad dissemination and universal access to all published research. These are the underlying objectives of open access publishing. There are societal and academic advantages to open dissemination of knowledge [1].

"Open access," however, has almost become a bad word in the medical community because of connotations of predatory journals and high publication fees. High publication fees are not pathognomonic for predatory journals-highly reputable journals that publish top research after rigorous review processes (not offered by predatory journals) can and do charge exorbitant publication fees. More importantly, however, open access should not be equated with high publication fees. Open access can be offered at no cost to authors.

I congratulated a colleague recently on a high impact publication that represented several years of carefully designed and executed translational research, only to discover that publication of that manuscript had consumed $€ 5500$ of his research budget. The draw of the impact factor seems to have justified the cost. If this manuscript had been published in the prestigious Nature, it would have cost $€ 9500$ for open access[2]. As researchers and authors, we should be asking what happens to those high publication fees. The publisher bears the cost of processing the manuscript for publication, which does involve professional editorial staff. However, the researchers provide the content of the published material, their scientific peers carry out the review on a voluntary basis, and even the scientific editors are generally not remunerated, or only at a rate that does not compare on an hourly basis to their academic salaries or clinical revenues. Lack of compensation for editors and reviewers is not necessarily a problem in itself, as it can be considered a return of service to the scientific community, but it becomes a significant problem when the publishers earn large profits from our academic services.

The bottom line is that a large part of those $€ 5500$ publication fees goes back to the publisher as profit. Scientific publishing is a lucrative business. Elsevier, which is one of the largest publishers of scientific research, is owned by the parent company RELX. RELX reported US $\$ 9.8 \mathrm{~B}$ profit in $2019,34 \%$ of which was derived from Elsevier[3]. This is an extraordinary sum of money that is taken out of the research enterprise and diverted to investors. In some cases, the $€ 5500$ publication fee may be provided by institutional accounts, but more often it is derived from a government funder, a charity funder, or perhaps a grateful patient donor. Those parties pay for the research to be conducted and pay again to read about the results of that research. How do we justify taking money from these sources to generate profit for publishers for the dissemination of research results?

These issues are not new, and initiatives have been undertaken to break down some of these financial barriers and push for financial transparency. Plan S represents an effort by European funding agencies demanding open access publication of research funded by these agencies (although they do not account for publication fees). Academic libraries, most notably the libraries of the University of California, have taken a stance in negotiating better deals with publishers to allow broader access to published literature. Library subscription fees represent an important component of revenue for the publishers. It takes large institutions or conglomerates to challenge the immense influence of the publishing companies.

There are two other stakeholders in the publication process who could also influence the current environment if they adopted a coordinated approach to work towards lower cost open access: industry partners advertising in scientific journals and the researchers publishing in scientific journals. Advertising revenue remains a large part of journal profits[4]. Those advertising dollars would likely cover open access publishing costs with no need for publication fees. If advertisers took a stand on the high cost of academic publishing, this could alter publishing practices. However, advertisers want the widest audience from the most prestigious journals, just as authors want the 
highest impact factor, so it is difficult to break the vicious cycle. On the authors' side there have been initiatives to boycott publishers in protest over the cost of publication. "The Cost of Knowledge" was one such initiative that was started in 2012[5], but it appears to have had little impact on publishing practices despite attracting the signatures of 18778 researchers from around the world[6].

Another approach is for medical organizations to provide open access journals with no publication fees. Several urological organizations have already done this, including the Canadian Urological Association, the Urological Society of India, the Brazilian Society of Urology, and the Chilean Society of Urology. The SIU has followed the model of these organizations with the

\section{References}

1. Tennant JP, Waldner F, Jacques DC, Masuzzo P, Collister LB, Hartgerink CHJ. The academic, economic and societal impacts of Open Access: an evidence-based review. F1000Res. $2016 \mathrm{Apr}$ 11;5:632. doi: 10.12688/f1000research.8460.3. eCollection 2016.

2. Brainard J. For €9500, Nature journals will now make your paper free to read. ScienceMag.org.2020. Available at: https://www. sciencemag.org/news/2020/11/9500-nature-journals-will-nowmake-your-paper-free-read. Accessed June 14, 2021. doi:10.1126/ science.abf8491

3. RELX. Annual report and financial statements 2019. Available at: https://www.relx.com/ /media/Files/R/RELX-Group/documents/ reports/annual-reports/2019-annual-report.pdf. Accessed June 14,2021 launch of the SIU Journal. These journals provide high quality editorial processing, peer review, and prompt open access publication. The efforts of all involved in the process are dedicated to knowledge dissemination and not profit, and any profit that is generated feeds back into the society that supports the activities of the members who are reading and publishing in the journal. These journals all provide excellent alternatives to the more recognized high-cost journals. The economics of urologic publishing relate to supply and demand. We have to ask ourselves as physicians and researchers what we can do to shift the demand away from the profitdriven large publishing houses and towards the open access free journals. If we shift, the impact factors that we all chase will follow.

4. Bhattarcharjee M. Publishers still rely on traditional revenue streams, research shows. What's New in Publishing. Available at: https://whatsnewinpublishing.com/publishers-still-rely-ontraditional-revenue-streams-research-shows/. Accessed June 14, 2021.

5. https://gowers.files.wordpress.com/2012/02/elsevierstatementfinal. pdf. Accessed June 14, 2021.

6. http://www.thecostofknowledge.com/. Accessed June 14, 2021. 